\title{
Stability of an extruded, linseed-based functional feed additive with the supplementation of vitamin $E$ and carvacrol
}

\author{
D. Čolović1 ${ }^{13}$, J. Lević' ${ }^{1}$ I. Čabarkapa', R. Čolović', Lj. Lević ${ }^{2}$ and I. Sedej' \\ University of Novi Sad \\ ${ }^{1}$ Institute of Food Technology, ${ }^{2}$ Faculty of Technology \\ Bul. cara Lazara 1, 21000 Novi Sad, Serbia
}

KEY WORDS: linseed-sunflower co-extrudate, extrusion, vitamin $\mathrm{E}$, carvacrol, a-linolenic acid, storage

Received: 29 January 2015

Revised: 16 October 2015

Accepted: 25 November 2015

${ }^{3}$ Corresponding author:

e-mail: dusica.ivanov@fins.uns.ac.rs

\begin{abstract}
The aim of this experiment was to investigate the storage stability of a linseed-sunflower meal co-extrudate, which was produced as a functional additive to improve the fatty acid composition of animal feed. Since a high content of a-linolenic acid causes low oxidative stability of this product, antioxidants, vitamin E (135 mg. $\left.100 \mathrm{~g}^{-1}\right)$ and carvacrol (200 mg $\left.100 \mathrm{~g}^{-1}\right)$, were added to the co-extrudate in order to prolong its shelf life. The ratio of linseed to sunflower meal in the extruded mixture was 50:50. The produced co-extrudate was stored in a climate chamber at $63 \pm 2{ }^{\circ} \mathrm{C}$ in order to examine changes during storage. The following chemical parameters were determined to detect changes in the fat phase of the co-extrudate: fatty acid composition, peroxide value and free fatty acid content. The samples were also monitored for their microbiological status. Although changes in the peroxide value as well as in the free fatty acid composition were significant, changes in the fatty acid content were minimal. Carvacrol gave excellent results in suppressing microorganism development, while it proved to be less effective as an antioxidant. Vitamin $E$, on the other hand, showed very good antioxidant activity, but had no significant effect on the growth and development of microorganisms. These two substances did not show any synergistic oxidative effect.
\end{abstract}

\section{Introduction}

The specificity of functional food or food supplements is reflected in their beneficial effects on the health and well-being of humans or animals. Consequently, the production of functional animal feed is constantly increasing. Recently, there has been growing interest in linseed and linseed oil due to their high concentration of linoleic acid (LA, 18:2, n-6) and especially $\alpha$-linolenic acid (ALA, 18:3, n-3), which are representatives of omega-6 (n-6) and omega-3 (n-3) polyunsaturated fatty acids (PUFAs). Moreover, linseed is the richest oilseed source of essential ALA (Juárez et al., 2010). As Csengeri (1996) pointed out, the cereals, oilseeds and their meals commonly used in animal diets usually contain a low level of n-3 fatty acids (FAs). Therefore, intensive inclusion of linseed in animal nutrition may significantly improve the FA composition of feed. Linseed's high ALA content is the main reason why it has drawn interest as a component in functional feed production. However, this characteristic makes linseed and its products highly susceptible to oxidation and oxidative deterioration, leading to low storage stability. 
Lipid oxidation is a problem frequently encountered in the storage of food or feed rich in fats, especially if the content of unsaturated FAs is high. Unsaturated FAs are the most sensitive to oxidation. Additionally, thermal processing of foodstuffs usually reduces their oxidative stability. Lipid oxidation (or autoxidation) causes the formation of highly reactive products, whose presence in feed has a negative impact on animal health. They also cause deterioration of the nutritional quality and sensory characteristics of food and feed (Laguerre et al., 2007). Lipid oxidation is a chain reaction occurring in three phases driven by the progressive influence of oxygen on fats and oils. In the initial phase, alkyl free radicals are formed from unsaturated FAs by removal of hydrogen. Afterwards, oxygen in the air reacts with an alkyl radical forming a peroxide radical. Peroxide radicals react with hydrogen from other compounds creating a hydroperoxide, which is then decomposed into peroxide radicals (Halliwell and Gutteridge, 2007). This stage of the reaction is known as the propagation phase. The last phase of lipid oxidation, called termination, involves linking of two free radicals creating a non-radical-compound.

Lipid oxidation can be prevented, or at least slowed, by the addition of antioxidants. These substances are able to suppress the effects of free radicals and prevent their negative oxidative activity by reacting with them. In this way, they disable the activation of oxygen and initiation of oxidative chain reactions with the constituents of cells of living organisms or food components. Antioxidants have to be available, stable and selective, they should also react only with free radicals. Numerous studies have shown that exogenous antioxidants, especially those entering with food, are essential for resistance of organisms to oxidative stress (Laguerre et al., 2007). Substances like vitamin E, ascorbic acid, eugenol, carvacrol or thymol have been used for many years because they often show additional properties resulting in antimicrobial, anticarcinogenic, antifungal, analgesic, insecticidal or anticoccidial effects (Lević et al., 2011).

Major problems during extrusion of materials rich in fats include lubrication and limited expansion of the produced extrudates. Another disadvantage, occurring in single-screw extrusion, is separation of the oil from the solid phase. Separation can change the nutritional composition of produced extrudate or cause unequal distribution of nutrients in the processed material, as it is in the case of extrusion of linseed. In order to overcome these problems, oil crops are often combined with another raw material, usually a protein component, having a good ability to adsorb oil. In the literature there are wellknown examples of co-extruding protein-rich mate- rials with linseed, where peas are usually the optional component (Thacker et al., 2004; Htoo et al., 2008). Sunflower meal is a protein-rich, relatively cheap byproduct of edible oil production, which shows great ability to adsorb oil $\left(2.05 \mathrm{~cm}^{3} \cdot \mathrm{g}^{-1}\right)$, and it is widely spread, particularly in Eastern Europe (Lević and Sredanović, 2012). Therefore, the presented investigation has been performed on a linseed-sunflower meal co-extrudate. Furthermore, this combination promises good results and has not been investigated yet.

Based on the above facts, the objective of this study was to investigate the storage stability of a linseed-sunflower meal co-extrudate produced as a functional supplement for animal feed, with or without the addition of vitamin E, carvacrol or a mixture of these two bioactive compounds. There are data in the published literature on the stability of whole and ground linseed during storage (Chen et al., 1994; Gopalakrishnan et al., 1996), but only limited data on the behaviour of extruded linseed or linseed co-extrudates could be found. Beside oxidative stability of the co-extrudate, changes in free fatty acid content (FFA), FA composition and microbial status of the product were monitored. We expected that the addition of vitamin $\mathrm{E}$ and carvacrol would retard oxidation and microbiological changes in the co-extrudate, and that the most intensive effects would be achieved by the addition of a mixture of the two compounds.

\section{Material and methods}

\section{Material}

The linseed and sunflower meal used to produce the co-extrudate originated from Serbia. Linseed of a native cultivar, 'Ljupko', was cultivated in the valley of the river Beli Timok (southeastern Serbia) and had the following chemical composition (expressed on dry matter - DM), \%: protein 22.52, ash 3.79, crude fibre 6.55 and fat 37.62 . Before processing, linseed was cleaned and impurities were removed. Sunflower meal was produced at the local oil factory in Vojvodina, Northern Serbian province, and contained $38.46 \%$ protein, $6.65 \%$ ash, $12.09 \%$ crude fibre and $1.98 \%$ fat (on DM basis).

\section{Extrusion process}

All materials were milled with use of a laboratory hammer mill (ABC Engineering; Zrenjanin, Serbia) with sieve openings of $4 \mathrm{~mm}$. The two compounds were mixed in a 50:50 (w/w) ratio in a doubleshaft paddle mixer-steam conditioner (Muyang SLHSJ0.2A; Jiangsu, China). Extrusion of 
the mixture was done on single-screw extruder (OEE 8, AMANDUS KAHL GmbH \& Co., KG, Germany), with a length/diameter ratio of $8.5: 1$. The extruder screw speed was set at $417.41 \mathrm{rpm}$ and the feeding rate was $32 \mathrm{~kg} \cdot \mathrm{h}^{-1}$.

\section{Storage of the co-extruded functional supplement}

The storage stability of the co-extrudate was investigated under accelerated conditions in a climate chamber (Binder kbf 240; Tuttlingen, Germany) with controlled temperature, relative humidity and air circulation settings. The investigations involved a Schaal oven stability test, which is commonly used for accelerated stability testing of fats and oils, as well as for food products that contain a considerable amount of fat (Liang and Schwarzer, 1998; Nawar, 1998). A modification of the method consisted of adjusting the relative humidity to a constant value of $40 \%$. The humidity value was selected based on the relative humidity measured in the room at the time of the experiment, using a digital manometer (Cole-Palmer; Illinois, USA). Air circulation was set at $100 \%$. The samples were placed in a climate chamber in $350 \mathrm{ml}$ glass jars, loosely sealed to allow contact with the air. Changes in the samples during storage were successively recorded every day during a period of thirteen days.

To examine the effect of individual antioxidants and a mixture of two antioxidants on the oxidative stability of the product, the following substances were used:

1. vitamin $\mathrm{E}$, $\min .50 \%$ DL-tocopheryl acetate $(=500$ former International Units of vitamin E or 336-TE per gram), with loss drying $<3 \%\left(4 \mathrm{~h}\right.$ at $\left.88^{\circ} \mathrm{C}\right)$ produced by BASF Corporation (New Jersey, USA). Near DLtocopheryl acetate, the product contained a matrix of lactose and caseinate, glycerin monostearate (E 471) and sodium hydroxide as a processing agent, as well as tricalcium phosphate (E 341) as an anti-caking agent, 2. commercial preparations of carvacrol $(>98 \%$ carvacrol), produced by Food Base Kft (Gödöllö, Hungary).

Vitamin E was added in an amount of 135 $\mathrm{mg} \cdot 100 \mathrm{~g}^{-1}$ of the co-extrudate, and carvacrol in an amount of $200 \mathrm{mg} \cdot 100 \mathrm{~g}^{-1}$ of the co-extrudate. The amounts of added antioxidants were chosen based on previously reported results. The results of samples with added antioxidants were compared with a control sample that contained no added substances.

\section{Analytical methods}

Knowing that the fat content in the produced co-extrudate was $20.57 \%$ (DM), the most important parameters of the supplement stability were those that reflected the stability of the fat phase. Therefore, changes in theperoxidevalue(PV)of the co-extrudate were recorded by measuring the presence of primary lipid oxidation products (peroxide and hydroperoxide), also by recording the daily changes in the acidity of the product, expressed as FFA. The second parameter was measured to determine if there was a release of FAs from the triglycerides in the product. Due to the high reactivity of unbound FAs (Nawar, 1998), we investigated whether the addition of antioxidants affected the intensity of changes in the FFA content.

Peroxide value (PV) was measured in the extracted fat phase of the co-extrudate according to AOCS Official Method Cd 8-53 (Firestone, 1989) and SRPS ISO 3960:2011. Cold extraction of the fat phase was performed with isooctane. The values were expressed as mmol $\mathrm{H}_{2} \mathrm{O}_{2} \cdot \mathrm{kg}^{-1}$ of fat phase extracted from the sample.

Free fatty acid (FFA) determination was also performed in the fat phase of the co-extrudate extracted with a diethyl ether/ethanol mixture (1:1) following the instructions given in AOCS Official Method Ca 5a-40 (Firestone, 1989) and JUS E.K8.026/1991 (Dimić and Turkulov, 2000). FFA was also expressed per kilogram of fat phase. The analyses were done in triplicate.

Fatty acid (FA) analysis. Supercritical fluid extraction (SFE) with $\mathrm{CO}_{2}$ was used for extraction of lipids from the samples, since it showed good results as a preparative technique for FA analysis. A LECO TFE2000 fat analyzer (Michigan, USA) was used for SFE, using $\mathrm{CO}_{2}$ with $99.995 \%$ purity. Extraction conditions were adjusted as explained in the paper by Ivanov et al. (2012). FA methyl esters were prepared from the extracted lipids by transmethylation that uses $14 \%(\mathrm{w} / \mathrm{w})$ boron trifluoride/methanol solution (Karlović and Andrić, 1996; Ivanov et al., 2012). The obtained samples were analysed by gas chromatography on an Agilent 7890A system (Agilent Technologies; Santa Clara, CA, USA) with a flame ionization detector (GC-FID), autoinjection module for liquid, equipped with fused silica capillary column (Supelco SP-2560 Capillary GC Column $100 \mathrm{~m} \times 0.25$ $\mathrm{mm}, \mathrm{d}=0.20 \mu \mathrm{m})$ (Supelco; Bellefonte, USA) and helium as a carrier gas (purity $=99.9997 \mathrm{vol} \%$, flow rate $=1.5 \mathrm{ml} \cdot \mathrm{min}^{-1}$ and pressure $=1.092 \mathrm{bar}$ ). The samples were injected in volume of $1 \mu \mathrm{l}$ in a split regime with a ratio of 30:1. The following temperature regime was applied: initial temperature $=140^{\circ} \mathrm{C}$, initial temperature hold time $=5 \mathrm{~min}$, heating rate $=3{ }^{\circ} \mathrm{C} \cdot \mathrm{min}^{-1}$, final temperature $=240^{\circ} \mathrm{C}$ and final temperature hold time $=10 \mathrm{~min}$. Nitrogen was used 
as the makeup gas. The FA peaks were identified by comparison of retention times with those of standards from 'Supelco 37 component FA methyl ester mix' (Supelco; Bellefonte, USA) and with data from an internal data library, based on previous experiments and FA methyl ester determination on a gas chromatograph - mass spectrometer (GC-MS). The analyses were performed in duplicate. The results were expressed as mass of individual fatty acid or fatty acid group $(\mathrm{g})$ in $100 \mathrm{~g}$ of fatty acids or as relative mass contents.

Microbiological analyses. Enumeration of total count of bacteria (TCB), coagulase-positive staphylococci, Clostridium perfringens, Salmonella spp., yeasts and molds were performed according to current ISO Standard Microbiological Methods (ISO, 2003a,b, 2004, 2006, 2008). Each test was performed in triplicate.

\section{Statistical analysis}

All of the results were expressed as means. Standard deviation of means (SD) was calculated using Microsoft Excel 2010 (Microsoft; Redmond, USA). Statistical analysis of experimental data was performed using STATISTICA version 11 (Statsoft, Inc., 2011). Analysis of variance (ANOVA) and the Tukey HSD test for comparison of sample means were used to analyse variations in measured PV of the samples, FA composition and FFA content. Differences between the means with a probability $P<0.05$ were accepted as statistically significant differences. The level of confidence was set at $95 \%$.

\section{Results}

Changes in the peroxide value (PV) of the samples of the co-extrudate, with or without added antioxidants, during storage are shown in Table 1. The highest PV during storage was found in the control sample, $46.32 \mathrm{mmol} \mathrm{H}_{2} \mathrm{O}_{2} \cdot \mathrm{kg}^{-1}$ of fat phase. The control sample, the sample with carvacrol, and the sample with the carvacrol and vitamin E mixture showed a rapid increase in PV on the fourth day of storage, with a maximum $\mathrm{PV}$ of $46.32,38.18$, and $40.84 \mathrm{mmol}$ $\mathrm{H}_{2} \mathrm{O}_{2} \cdot \mathrm{kg}^{-1}$ of fat phase, respectively. A rapid increase in PV in the sample with vitamin $\mathrm{E}$ also started on the fourth day of storage, but its maximum PV (36.55 mmol $\mathrm{H}_{2} \mathrm{O}_{2} \cdot \mathrm{kg}^{-1}$ ) was recorded on the fifth day.

Vitamin $\mathrm{E}$, carvacrol and their mixture were added to the samples in order to examine their antioxidant effect on this specific functional supplement. As shown in Table 1, the lowest value of the peak was measured in the sample with vitamin $\mathrm{E}$ ( $36.55 \mathrm{mmol} \mathrm{H}_{2} \mathrm{O}_{2} \cdot \mathrm{kg}^{-1}$ ), which leads to the conclusion that vitamin $\mathrm{E}$ showed better antioxidant activity than carvacrol (the PV peak was $38.18 \mathrm{mmol}$ $\mathrm{H}_{2} \mathrm{O}_{2} \cdot \mathrm{kg}^{-1}$ ). Also, $\mathrm{PV}$ reached a peak on the fifth day in the sample with vitamin $E$, which showed that oxidation in this sample was slower in comparison with the other samples.

Changes in FFA in the examined samples during storage are shown in Figure 1. As can be seen, FFA increased significantly $(P \leq 0.05)$ during storage in all samples. The increase was the smallest in the sample with the mixture of carvacrol and vitamin $\mathrm{E}$

Table 1. Peroxide value of co-extrudate samples

\begin{tabular}{|c|c|c|c|c|}
\hline \multirow{2}{*}{$\begin{array}{l}\text { Days } \\
\text { of storage }\end{array}$} & \multicolumn{4}{|c|}{ Peroxide value, $\mathrm{mmol} \mathrm{H}_{2} \mathrm{O}_{2} \cdot \mathrm{kg}^{-1}$ of fat phase } \\
\hline & control & control + carvacrol & control + vitamin $\mathrm{E}$ & control + vitamin E + carvacrol \\
\hline 0 & $0.92^{\mathrm{a} 1} \pm 0.01$ & $0.92^{\mathrm{a} 1} \pm 0.01$ & $0.92^{\mathrm{a} 1} \pm 0.02$ & $0.92^{\mathrm{a} 1} \pm 0.01$ \\
\hline 1 & $1.3^{\mathrm{a} 2} \pm 0.01$ & $0.93^{b 1} \pm 0.01$ & $0.92^{b 1} \pm 0.01$ & $0.94^{b 1} \pm 0.01$ \\
\hline 2 & $4.57^{\mathrm{ac} 3} \pm 0.02$ & $4.81^{\mathrm{a} 2} \pm 0.02$ & $2.53^{\text {b3 }} \pm 0.02$ & $4.41^{\mathrm{c} 2} \pm 0.02$ \\
\hline 3 & $5.58^{\mathrm{a} 4} \pm 0.02$ & $5.88^{\mathrm{a} 3} \pm 0.01$ & $4.2^{64} \pm 0.01$ & $6.59^{c 3} \pm 0.02$ \\
\hline 4 & $46.32^{\mathrm{a} 5} \pm 0.14$ & $38.18^{b 4} \pm 0.11$ & $17.02^{c 5} \pm 0.09$ & $40.84^{\mathrm{d} 4} \pm 0.15$ \\
\hline 5 & $16.95^{\mathrm{a} 6} \pm 0.09$ & $13.18^{\mathrm{b} 5} \pm 0.05$ & $36.55^{c 6} \pm 0.07$ & $24.69^{d 5} \pm 0.10$ \\
\hline 6 & $1.54^{\mathrm{a} 7} \pm 0.01$ & $3.57^{\mathrm{b} 6} \pm 0.01$ & $14.66^{\mathrm{c} 7} \pm 0.02$ & $3.05^{b 6} \pm 0.02$ \\
\hline 7 & $1.76^{\mathrm{a} 8} \pm 0.01$ & $3.89^{\mathrm{b7}} \pm 0.01$ & $1.92^{\mathrm{a} 8} \pm 0.01$ & $3.06^{b 6} \pm 0.01$ \\
\hline 8 & $2.05^{a 9} \pm 0.01$ & $4.12^{b 8} \pm 0.01$ & $2.14^{\mathrm{ac} 9} \pm 0.02$ & $3.31^{67} \pm 0.02$ \\
\hline 9 & $2.69^{\mathrm{a} 10} \pm 0.02$ & $4.48^{b 9} \pm 0.01$ & $2.27^{\mathrm{a} 10} \pm 0.02$ & $3.46^{c 8} \pm 0.02$ \\
\hline 10 & $2.23^{\mathrm{a} 11} \pm 0.02$ & $2.67^{\mathrm{a} 10} \pm 0.01$ & $2.41^{\mathrm{a} 11} \pm 0.02$ & $3.62^{b 9} \pm 0.01$ \\
\hline 11 & $1.89^{\mathrm{a} 12} \pm 0.02$ & $2.08^{b 11} \pm 0.03$ & $2.65^{b 12} \pm 0.01$ & $3.99^{c 10} \pm 0.02$ \\
\hline 12 & $1.64^{\mathrm{a} 13} \pm 0.01$ & $1.87^{\mathrm{a} 12} \pm 0.02$ & $2.91^{\mathrm{b} 13} \pm 0.02$ & $4.12^{\mathrm{c} 11} \pm 0.02$ \\
\hline 13 & $1.66^{\mathrm{a} 13} \pm 0.01$ & $1.91^{\mathrm{a} 12} \pm 0.02$ & $2.5^{\mathrm{b} 14} \pm 0.01$ & $4.01^{\mathrm{c} 12} \pm 0.01$ \\
\hline
\end{tabular}

results are presented as mean $\pm S D, n=3$; different superscript letter whitin the same raw indicate significant differences $(P<0.05)$; different superscripts number whitin the same column indicate significant differences $(P<0.05)$ 


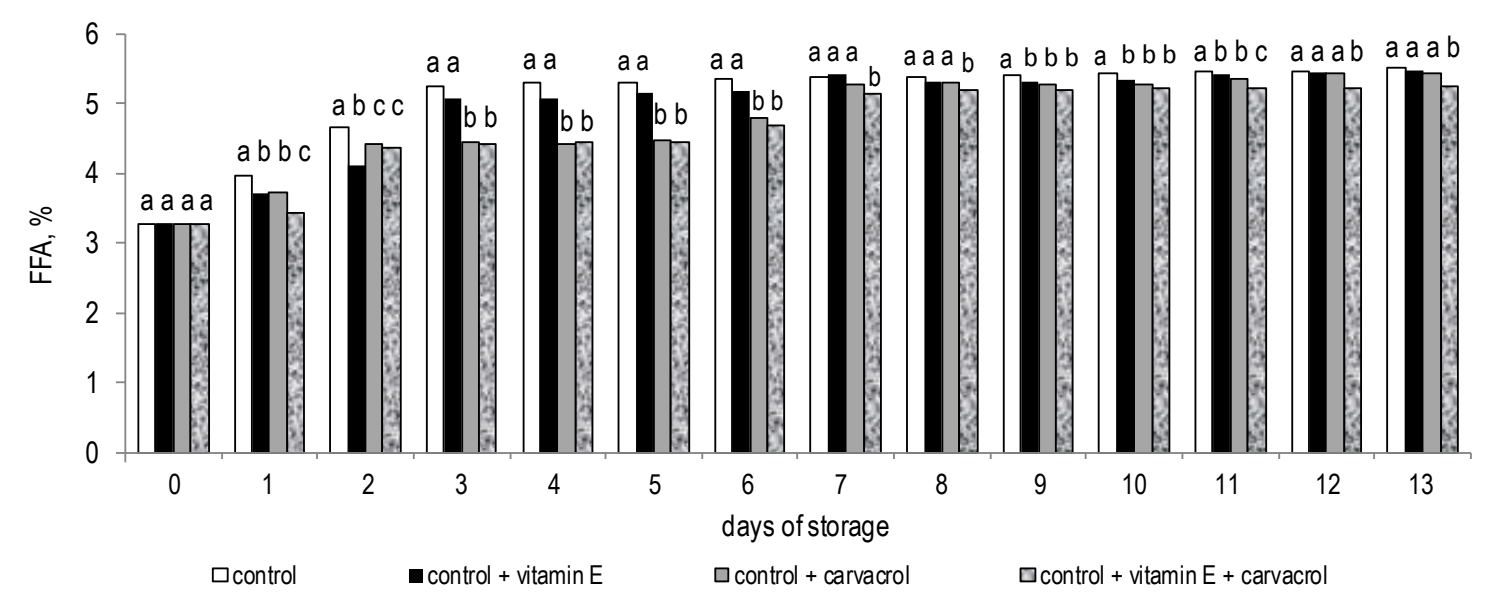

Figure 1. Free fatty acids (FFA) changes in samples during storage period; $a, b, c$ bars with different letters within the same day differ significantly $(P<0.05)$

(from $3.28 \%$ to $5.25 \%$ ). By the sixth day of storage, FFA in the samples with carvacrol and a mixture of carvacrol and vitamin E were remarkably lower (4.68\% and $4.78 \%$, respectively) than in the sample with vitamin E $(5.19 \%)$. On the last day of storage, FFA in samples with vitamin $\mathrm{E}$ and carvacrol were almost equal (5.48\% and 5.42\%) and did not significantly differ from each other $(P=0.08)$. In the control sample, FFA reached a value of $5.25 \%$ on the third day. This value increased only by $0.26 \%$ by the end of storage. Similar stabilization of FFA was observed in the other samples.

The main reason for monitoring the changes in FA composition of the co-extrudate during storage was the remarkable amount of unsaturated FAs, with emphasis on ALA. The results of changes in fatty acid composition during storage are shown in Table 2. The ALA content in the control sample did not change significantly $(P=0.13)$, although a slight reduction was recorded. It amounted to $48.43 \%$ on day zero of storage and decreased to $47.52 \%$ on the thirteenth day. The same trend was also observed in the samples with added antioxidants. Minimal changes in ALA content were detected in the sample with added vitamin E, whereas the smallest content of this FA was recorded on the thirteenth day of storage and equaled $47.66 \%$.

The contents of oleic (C18:1) and palmitic (C16:0) acids slightly increased in all samples (Table 2). However, these changes were not statistically significant $(P>0.05)$. The smallest increase in FA contents was detected in the sample with vitamin E (from $25.49 \%$ and $5.93 \%$ to $25.78 \%$ and $6.20 \%$, respectively).

Pearson's correlation coefficients were determined in order to test the significance of bilateral relationships between contents of individual FAs, as presented in Table 3. The ALA content had a significant negative correlation with $\mathrm{C} 18: 1$ in all samples $(\mathrm{r}=-0.73,-0.68,-0.87$ and -0.93 for the control sample, sample with vitamin E, sample with carvacrol and sample with the mixture of antioxidants, respectively). The correlation between ALA and C18:2 was significantly negative in samples with added antioxidants $(r=-0.94,-0.93$ and -0.99 , for the sample with vitamin E, sample with carvacrol and sample with the antioxidant mixture, respectively). This means that as the ALA content decreased, the contents of oleic and linoleic acids increased. Similarly, C18:2 acid had a significant negative correlation with the $\mathrm{C} 18: 0$ content $(r=-0.71,-0.79,-0.84,-0.82$ for the control, vitamin E, carvacrol and antioxidant mixture samples, respectively).

The microbiological safety of the untreated mixture of linseed and sunflower meal was investigated before production of the co-extrudate, and the same analyses were done after extrusion of the mixture (Table 4). There was a statistically significant reduction $(P=0.032)$ in TCB $\left(15000 \mathrm{cfu} \cdot \mathrm{g}^{-1}\right.$ before and $11000 \mathrm{cfu} \cdot \mathrm{g}^{-1}$ after extrusion) in the produced feed supplement, as a result of the extrusion process.

The changes in the TCB in the samples during storage are given in Figure 2. Since the other microbiological parameters were below the limit of detection in all samples, these results are not shown. The lowest TCB was measured after thirteen days of storage in the sample with added carvac$\mathrm{rol}$, and equaled $600 \mathrm{cfu} \cdot \mathrm{g}^{-1}$. TCB was the highest in the control sample after thirteen days of storage, $1300 \mathrm{cfu} \cdot \mathrm{g}^{-1}$. The same value was found in the sample with vitamin E, although TCB in this sample during storage was lower than in the control. Unlike vitamin E, carvacrol showed very strong antimicrobial activity. TCB in the sample with carvacrol was statistically lower $(P \leq 0.05)$ than in the control during the entire storage period. The most evident difference in TCB occurred on the first day of storage between the control sample and the sample with carvacrol $\left(5000 \mathrm{cfu} \cdot \mathrm{g}^{-1}\right)$. 
Table 2. Changes in fatty acid composition during storage period

\begin{tabular}{|c|c|c|c|c|c|c|c|c|c|c|c|c|c|c|}
\hline Days of storage & 0 & 1 & 2 & 3 & 4 & 5 & 6 & 7 & 8 & 9 & 10 & 11 & 12 & 13 \\
\hline \multicolumn{15}{|c|}{ Fatty acid, $\%$ of total fatty acids } \\
\hline \multicolumn{15}{|l|}{ Control sample } \\
\hline $\mathrm{C} 14: 0$ & 0.04 & 0.05 & 0.06 & 0.06 & 0.11 & 0.05 & 0.04 & 0.07 & 0.06 & 0.05 & 0.06 & 0.05 & 0.05 & 0.06 \\
\hline C16:0 & 5.93 & 6.05 & 6.39 & 6.38 & 6.20 & 6.20 & 6.19 & 6.23 & 6.20 & 6.24 & 6.20 & 6.25 & 6.21 & 6.24 \\
\hline C16:1 & 0.08 & 0.10 & 0.13 & 0.09 & 0.08 & 0.07 & 0.08 & 0.07 & 0.09 & 0.06 & 0.07 & 0.08 & 0.04 & 0.06 \\
\hline C18:0 & 4.89 & 4.69 & 4.55 & 4.65 & 4.66 & 4.67 & 4.65 & 4.69 & 4.70 & 4.65 & 4.64 & 4.50 & 4.51 & 4.62 \\
\hline C18:1 & 25.49 & 25.25 & 25.16 & 25.14 & 25.46 & 25.62 & 25.64 & 25.69 & 25.68 & 25.75 & 25.76 & 25.80 & 25.87 & 25.88 \\
\hline C18:2 n-6 & 15.13 & 15.79 & 15.69 & 15.73 & 15.64 & 15.60 & 15.69 & 15.60 & 15.64 & 15.59 & 15.67 & 15.71 & 15.63 & 15.62 \\
\hline C18:3n-3 & 48.43 & 48.07 & 48.02 & 47.93 & 47.85 & 47.79 & 47.71 & 47.65 & 47.63 & 47.63 & 47.60 & 47.61 & 47.60 & 47.52 \\
\hline \multicolumn{15}{|c|}{ Control + vitamin E } \\
\hline C14:0 & 0.04 & 0.05 & 0.08 & 0.10 & 0.12 & 0.13 & 0.10 & 0.10 & 0.07 & 0.08 & 0.08 & 0.05 & 0.05 & 0.05 \\
\hline C16:0 & 5.93 & 6.05 & 6.12 & 6.14 & 6.16 & 6.14 & 6.20 & 6.21 & 6.18 & 6.16 & 6.20 & 6.21 & 6.20 & 6.20 \\
\hline C16:1 & 0.08 & 0.09 & 0.14 & 0.18 & 0.17 & 0.19 & 0.07 & 0.09 & 0.10 & 0.09 & 0.04 & 0.07 & 0.06 & 0.07 \\
\hline C18:0 & 4.89 & 4.90 & 4.91 & 4.90 & 4.89 & 4.91 & 4.87 & 4.87 & 4.88 & 4.84 & 4.80 & 4.75 & 4.75 & 4.75 \\
\hline C18:1 & 25.49 & 25.44 & 25.41 & 25.46 & 25.37 & 25.48 & 25.57 & 25.59 & 25.62 & 25.70 & 25.71 & 25.74 & 25.76 & 25.78 \\
\hline C18:2n-6 & 15.13 & 15.20 & 15.22 & 15.23 & 15.30 & 15.36 & 15.42 & 15.39 & 15.40 & 15.41 & 15.49 & 15.48 & 15.50 & 15.50 \\
\hline C18:3n-3 & 48.43 & 448.27 & 48.12 & 47.99 & 47.85 & 47.79 & 47.77 & 47.75 & 47.75 & 47.72 & 47.68 & 47.70 & 47.68 & 47.66 \\
\hline \multicolumn{15}{|c|}{ Control + carvacrol } \\
\hline C14:0 & 0.03 & 0.05 & 0.08 & 0.13 & 0.14 & 0.13 & 0.08 & 0.09 & 0.07 & 0.10 & 0.08 & 0.08 & 0.07 & 0.06 \\
\hline C16:0 & 5.91 & 6.05 & 6.12 & 6.14 & 6.16 & 6.14 & 6.24 & 6.22 & 6.19 & 6.16 & 6.20 & 6.21 & 6.23 & 6.21 \\
\hline C16:1 & 0.10 & 0.09 & 0.14 & 0.18 & 0.17 & 0.19 & 0.07 & 0.09 & 0.10 & 0.09 & 0.08 & 0.11 & 0.08 & 0.08 \\
\hline C18:0 & 4.93 & 4.90 & 4.93 & 4.90 & 4.89 & 4.91 & 4.87 & 4.87 & 4.88 & 4.86 & 4.80 & 4.75 & 4.75 & 4.77 \\
\hline C18:1 & 25.37 & 25.44 & 25.41 & 25.46 & 25.47 & 25.48 & 25.57 & 25.61 & 25.64 & 25.68 & 25.71 & 25.76 & 25.76 & 25.79 \\
\hline C18:2n-6 & 15.21 & 15.20 & 15.22 & 15.23 & 15.32 & 15.36 & 15.42 & 15.39 & 15.41 & 15.45 & 15.49 & 15.48 & 15.50 & 15.50 \\
\hline C18:3n-3 & 48.43 & 48.27 & 48.10 & 47.96 & 47.85 & 47.79 & 47.75 & 47.73 & 47.71 & 47.66 & 47.64 & 47.61 & 47.61 & 47.59 \\
\hline \multicolumn{15}{|c|}{ Control + vitamin E + carvacrol } \\
\hline $\mathrm{C} 14: 0$ & 0.04 & 0.04 & 0.05 & 0.04 & 0.07 & 0.06 & 0.08 & 0.09 & 0.07 & 0.09 & 0.08 & 0.09 & 0.07 & 0.06 \\
\hline C16:0 & 5.93 & 5.97 & 6.00 & 6.01 & 6.00 & 6.08 & 6.10 & 6.12 & 6.11 & 6.11 & 6.12 & 6.12 & 6.13 & 6.14 \\
\hline C16:1 & 0.08 & 0.09 & 0.11 & 0.12 & 0.12 & 0.09 & 0.09 & 0.10 & 0.09 & 0.09 & 0.09 & 0.09 & 0.09 & 0.08 \\
\hline C18:0 & 4.89 & 4.90 & 4.91 & 4.90 & 4.89 & 4.91 & 4.88 & 4.87 & 4.88 & 4.82 & 4.80 & 4.75 & 4.77 & 4.78 \\
\hline C18:1 & 25.49 & 25.44 & 25.41 & 25.46 & 25.47 & 25.48 & 25.58 & 25.61 & 25.66 & 25.70 & 25.71 & 25.77 & 25.76 & 25.76 \\
\hline C18:2n-6 & 15.13 & 15.16 & 15.19 & 15.21 & 15.30 & 15.36 & 15.42 & 15.43 & 15.43 & 15.49 & 15.52 & 15.53 & 15.54 & 15.56 \\
\hline C18:3n-3 & 48.43 & 48.40 & 48.33 & 48.26 & 48.15 & 47.99 & 47.85 & 47.79 & 47.75 & 47.70 & 47.68 & 47.65 & 47.64 & 47.62 \\
\hline
\end{tabular}

results are presented as mean, $n=3$

Table 3. Correlation coefficients between contents of individual fatty acids within the same group of samples

\begin{tabular}{|c|c|c|c|c|c|c|c|c|c|c|c|c|}
\hline & \multicolumn{6}{|c|}{ Control sample } & \multicolumn{6}{|c|}{ Control + vitamin E } \\
\hline & $\mathrm{C} 14: 0$ & C16:0 & $\mathrm{C} 16: 1$ & C18:0 & C18:1 & C18:2 & C14:0 & $\mathrm{C} 16: 0$ & C16:1 & C18:0 & C18:1 & C18:2 \\
\hline$\overline{\mathrm{C} 16: 0}$ & 0.260 & 1 & & & & & 0.3 & 1 & & & & \\
\hline C16:1 & 0.076 & 0.197 & 1 & & & & $0.694^{1}$ & -0.15 & 1 & & & \\
\hline C18:0 & -0.08 & $-0.70^{1}$ & 0.075 & 1 & & & 0.524 & -0.51 & $0.668^{1}$ & 1 & & \\
\hline C18:1 & -0.14 & -0.14 & -0.811 & -0.22 & 1 & & 0.47 & $0.543^{1}$ & $-0.73^{1}$ & $-0.90^{1}$ & 1 & \\
\hline C18:2 & 0.208 & $0.623^{1}$ & 0.2 & $-0.71^{1}$ & -0.13 & 1 & -0.04 & $0.852^{1}$ & -0.49 & $-0.79^{1}$ & $0.852^{1}$ & 1 \\
\hline \multirow[t]{3}{*}{ C18:3 n-3 } & -0.13 & -0.46 & 0.531 & $0.619^{1}$ & $-0.73^{1}$ & -0.52 & -0.26 & $-0.94^{1}$ & 0.213 & $0.605^{1}$ & $-0.68^{1}$ & $-0.94^{1}$ \\
\hline & \multicolumn{6}{|c|}{ Control + carvacrol } & \multicolumn{6}{|c|}{ Control + vitamin E + carvarcol } \\
\hline & $\mathrm{C} 14: 0$ & $\mathrm{C} 16: 0$ & C16:1 & C18:0 & C18:1 & C18:2 & C14:0 & C16:0 & C16:1 & C18:0 & C18:1 & $\mathrm{C} 18: 2$ \\
\hline $\mathrm{C} 16: 0$ & 0.357 & 1 & & & & & $0.773^{1}$ & 1 & & & & \\
\hline C16:1 & $0.753^{1}$ & -0.19 & 1 & & & & -0.24 & -0.28 & 1 & & & \\
\hline C18:0 & 0.175 & $-0.62^{1}$ & 0.483 & 1 & & & $-0.55^{1}$ & $-0.68^{1}$ & $0.559^{1}$ & 1 & & \\
\hline C18:1 & -0.13 & $0.730^{1}$ & $-0.55^{1}$ & $-0.92^{1}$ & 1 & & $0.677^{1}$ & $0.845^{1}$ & $-0.59^{1}$ & $-0.92^{1}$ & 1 & \\
\hline C18:2 & 0.002 & $0.769^{1}$ & -0.48 & $-0.84^{1}$ & $0.946^{1}$ & 1 & $0.792^{1}$ & $0.961^{1}$ & -0.36 & $-0.82^{1}$ & 0.926 & 1 \\
\hline C18:3 n-3 & -0.32 & $-0.92^{1}$ & 0.213 & $0.734^{1}$ & $-0.87^{1}$ & $-0.93^{1}$ & $-0.81^{1}$ & $-0.97^{1}$ & 0.367 & $0.782^{1}$ & $-0.93^{1}$ & $-0.99^{1}$ \\
\hline
\end{tabular}


Table 4. Microbiological status of untreated mixture of linseed-sunflower meal and co-produced extrudates

\begin{tabular}{lllll}
\hline Analysis & Untreated mixture & SD & Co-extrudate & SD \\
\hline Total number of aerobic bacteria, cfu $\cdot \mathrm{g}^{-1}$ & 15000 & \pm 96 & 11000 & \pm 75 \\
Coagulase positive Staphylococci, cfu $\cdot \mathrm{g}^{-1}$ & $<100$ & \pm 15 & $<100$ & \pm 17 \\
Clostridium perfringens, cfu $\cdot \mathrm{g}^{-1}$ & $<10$ & \pm 1 & $<10$ & \pm 1 \\
Salmonella spp. & $\mathrm{ND}$ in $50 \mathrm{~g}$ & & $\mathrm{ND}$ in $50 \mathrm{~g}$ & \\
Total number of molds and yeasts, $\mathrm{cfu} \cdot \mathrm{g}^{-1}$ & $<100$ & \pm 13 & $<100$ & \pm 6 \\
\hline
\end{tabular}

results are presented as mean, $n=3 ; N D-$ not detected

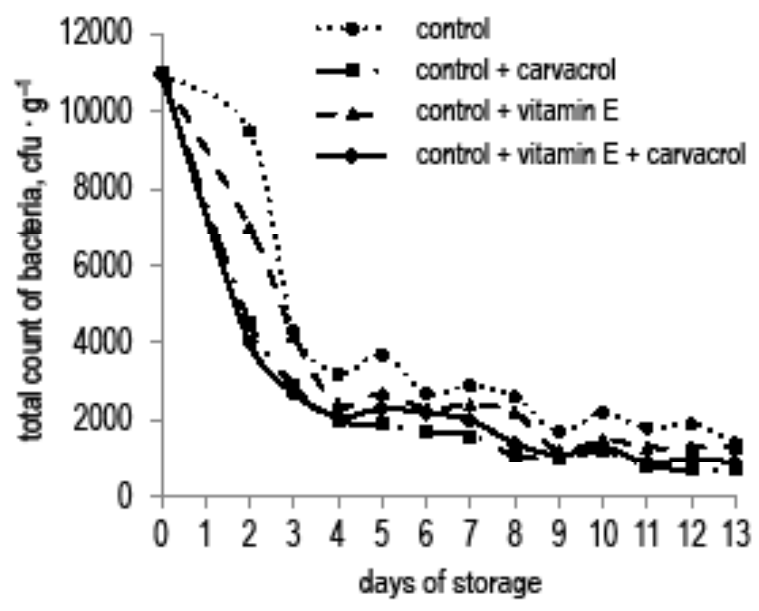

Figure 2. Total count of bacteria in co-extrudate samples during storage in climate chamber, $\mathrm{cfu} \cdot \mathrm{g}^{-1}$

\section{Discussion}

Under the accelerated storage conditions used in the experiment, all samples reached high PV of the fat phase in a very short period of four to five days. These results are consistent with the literature data. After only six days of storage, Michotte et al. (2011) recorded in their study of linseed oil stability at $60^{\circ} \mathrm{C}$ a very high $\mathrm{PV}$ of more than $60 \mathrm{meq} \cdot \mathrm{g}^{-1}$ (120 $\mathrm{mmol} \mathrm{H}_{2} \mathrm{O}_{2} \cdot \mathrm{kg}^{-1}$ ) in the control sample, or between 30 and $60 \mathrm{meq} \cdot \mathrm{kg}^{-1}$ (60 and $120 \mathrm{mmol}$ $\left.\mathrm{H}_{2} \mathrm{O}_{2} \cdot \mathrm{kg}^{-1}\right)$ in samples with added antioxidants.

After reaching a maximum $(\mathrm{PV}=46.32,38.18$, 36.55 and $40.84 \mathrm{mmol} \mathrm{H}_{2} \mathrm{O}_{2} \cdot \mathrm{kg}^{-1}$ of fat phase for the control sample, the samples with vitamin E, carvacrol and a mixture of both, respectively), the PV drastically decreased in all tested samples. This can be explained by primary oxidation products being transitory compounds that are unstable and very susceptible to further oxidation and decomposition to the secondary products such as aldehydes, ketones, lower alcohols, etc. (Nawar, 1998; Shaidi, 2002). Therefore, after a certain time, $P V$ would rapidly decrease (in this experiment, after the fourth or fifth day of storage), which marks the moment when the degradation of primary products (formation of secondary oxidation products) becomes many times faster than their formation.
Beside PV, determination of malondialdehyde (MDA) also enables precise evaluation of oxidative stress and oxidative stability, especially in animal tissues and animal products. After peroxidation of PUFA, PUFA peroxides are decomposed into more complex forms and into reactive species such as MDA and 4-hydroxynonenal (4-HNE) (Konieczka et al., 2014). The literature data shows that MDA can be determined in animal feeds, such as those for chickens and hens (Czauderna et al., 2011). However, several authors have presented the standpoint that MDA is an end-product generated by decomposition of arachidonic acid and larger PUFAs (Esterbauer et al., 1991). Bearing in mind the FA composition of linseed and sunflower meal, we chose PV as the more conventional measurement of oxidative stability of the produced co-extrudate. Our further investigations will focus on MDA analysis in the presented product, as well as on comparison between PV and MDA changes during storage period.

The physical form of extrudates is one of the main reasons for their high susceptibility to oxidation during storage. Extruded material is characterized by a porous structure with numerous cavities, which increases the contact surface between the product and oxygen and enables penetration of oxygen into the interior of the co-extrudate (Zademowski et al., 1997). In this way, oxidation occurs not only on the outer surface of the granules, but rather evenly throughout its volume. In addition, extrusion reduces the concentration of naturally occurring antioxidants in the treated material (Zademowski et al., 1999).

The PVs of the samples with added antioxidants were significantly lower $(P \leq 0.05)$ than of the control sample after the first day of storage $(0.92-0.94 \mathrm{mmol}$ $\mathrm{H}_{2} \mathrm{O}_{2} \cdot \mathrm{kg}^{-1}$ in comparison with $1.3 \mathrm{mmol} \mathrm{H}_{2} \mathrm{O}_{2} \cdot \mathrm{kg}^{-1}$ of fat phase). Statistically the most significant difference in PVs was found between the control sample and the sample with added vitamin E $(P=0.0002)$ on the fourth day of storage. This is one more indicator that vitamin E showed the most intensive antioxidant effect on the examined substrate (co-extrudate). Interestingly, the addition of the mixture of carvacrol and vitamin $\mathrm{E}$ did not show increased antioxidant activity. On the contrary, it was lower than the 
activity of the individual components separately (Table 2). Accordingly, there was no synergistic effect of the two antioxidants, which was the goal when they were both added to the sample. It seems that one of the compounds inhibited the antioxidant effect of the other, or it acted as a pro-oxidant. It is known in the literature that antioxidants can show a pro-oxidative effect (Gordon, 1990). Kontush et al. (1996), for example, demonstrated the pro-oxidative effect of $\alpha$-tocopherol in lowdensity lipoprotein isolated from healthy patients. The pro-oxidative effect of phenolic compounds is explained by the formation of semichinon or superoxide radicals $\left(\mathrm{O}_{2}^{-}\right)$in the process of autooxidation. These radicals are very reactive and continue to accelerate auto-oxidation of phenols in the formation of $\mathrm{H}_{2} \mathrm{O}_{2}$ (Mochiuzuki et al., 2002). Thus, further experiments will include investigation of several different concentrations of vitamin $\mathrm{E}$ and carvacrol in order to determine whether these two components can show any synergistic oxidative effect and at which concentrations. Another direction is to change storage conditions, which might also have influenced the oxidative activity of added substances.

The increase in FFA in the samples during storage was most likely caused by the presence of moisture in the air (Malcolmson et al., 2000), as well as by damage of seeds during grinding and then during extrusion. Damaged seeds are more susceptible to the lipolytic activities of endogenous enzymes, such as plant lipase, so degradation of triglycerides is easier and faster (Malcolmson et al., 2000; Dierick and Decuypere, 2002). The primary products of lipolytic reactions are free FAs (O'Connor et al., 1992). As previously shown, at the end of the storage period, stabilization of FFA was detected. Changes in FFA were not statistically significant in any of the examined samples after the seventh day of storage. A possible reason could be inactivation of the enzyme lipase due to the long exposure of the samples to a temperature of $63 \pm 2{ }^{\circ} \mathrm{C}$.

Several groups of authors examined the impact of antioxidants on FFA, presenting heterogeneous results. Hettiarachchy and Barr (1991) showed that addition of citric acid and L-ascorbic-6-palmitate, alone or in combination, reduces formation of FFA in samples of milled linseed stored at $26^{\circ} \mathrm{C}$. Rahman et al. (2008) examined the effect of butylated hydroxyanisole (BHA), butylated hydroxytoluene (BHT) and propyl gallate on the FFA and $\mathrm{PV}$ of sesame oil during storage. According to their results, addition of BHA resulted in lower FFA and $\mathrm{PV}$ of the examined samples in comparison with the control sample. BHT was proven to be suitable for prevention of an increase in FFA, and propyl gallate showed a more intense effect in the prevention of the formation of primary products of peroxidation (Rahman et al., 2008).

As already mentioned, the ALA content slightly decreased in all samples (from $48.43 \%$ to approx. $47.60 \%$ ). The reason for that was most likely FA oxidation and degradation of unsaturated double bonds. Small changes in the FA composition of linseed and other nutrients during storage are not uncommon, although changes in the PV and FFA could be significant at the same time. Malcolmson et al. (2000) found that there were almost no changes in the FA composition of untreated linseed stored at temperatures of $23 \pm 2{ }^{\circ} \mathrm{C}$ in paper bags, while the FFA value significantly increased $(P \leq 0.05)$. The FFA value was three times higher than in the initial sample after 128 days of storage. These authors attributed the increase in the value of FFA to the function of endogenous enzymes of linseed. In the same samples, there was an increase in PV, which was the highest on the 66 day of storage, and afterwards it began to decrease.

Gopalakrishnan et al. (1996) also investigated the storage stability of untreated linseed, which was packed in plastic bags and sealed. The samples were stored at two temperatures: room temperature and $5^{\circ} \mathrm{C}$. It was found that no changes in the FA composition occurred at the lower temperature, while at the higher temperature, the content of ALA decreased from $59.2 \%$ to $57.6 \%$ after 60 days of storage. In the same samples, the initial PV was $1.1 \mathrm{meq} \cdot \mathrm{kg}^{-1}$ of fat phase, and had risen to $3.5 \mathrm{meq} \cdot \mathrm{kg}^{-1}$ at room temperature, or to $3 \mathrm{meq} \cdot \mathrm{kg}^{-1}$ at $5^{\circ} \mathrm{C}$ by the end of the storage period. The same authors examined the changes that occur in commercial diets for chickens under identical conditions. FA composition was not changed significantly, especially at a storage temperature of $5^{\circ} \mathrm{C}$. However, PV increased from an initial $31 \mathrm{meq} \cdot \mathrm{kg}^{-1}$ to $89 \mathrm{meq} \cdot \mathrm{kg}^{-1}$ at room temperature, and to $79.1 \mathrm{meq} \cdot \mathrm{kg}^{-1}$ at $5^{\circ} \mathrm{C}$ after thirty days of storage. The FFA of samples increased from $21.9 \%$ to $30.1 \%$. As the authors concluded, the individual raw materials during storage showed far lower susceptibility to auto-oxidation than the mixtures, which is probably due to the interaction of materials (Gopalakrishnan et al., 1996).

Extrusion of the material under conditions that are commonly used in food production destroys most molds and yeasts, while reduction of bacteria depends on the applied conditions (Chessari and Shellahewa, 2001). Streptococcus thermophilus is successfully destroyed by extrusion at a temperature of $130^{\circ} \mathrm{C}$ and low friction forces in the barrel of 
the extruder. This leads to the conclusion that the reduction of bacteria is based on thermal treatment (Quéguiner et al., 1989). With increased storage time, the degree of reduction of the total bacteria count was less intensive. Since this phenomenon occurred in all samples, the reduction was probably due to the influence of high temperature, which caused the reduction of $a_{w}$ values as a consequential effect. Bearing in mind the storage temperature of $63 \pm 2{ }^{\circ} \mathrm{C}$, the achieved reduction in the total count of bacteria (TCB) was expected. This temperature disabled growth of microorganisms, with the exception of mesophilic and thermophilic extremes.

The impact of added carvacrol and vitamin $\mathrm{E}$ also cannot be disregarded. Carvacrol, an active phenolic constituent of various essential oils, is known for its wide spectrum of activity against both gram-positive and gram-negative microorganisms (Hammer et al., 1999; Burt, 2004). The effectiveness of carvacrol as a natural antimicrobial is well established; however, the mechanism of action is less understood and is believed to be associated with damage to the cell membrane (Ultee et al., 2002; Veldhuizen et al., 2006). The results of our experiment confirmed strong antimicrobial activity of carvacrol. As already mentioned, TCB significantly differed $(P<0.05)$ between the control sample and sample with added carvacrol $\left(5000 \mathrm{cfu} \cdot \mathrm{g}^{-1}\right)$. This difference was also high in comparison with the sample with vitamin E $\left(3500 \mathrm{cfu} \cdot \mathrm{g}^{-1}\right)$, while TCB in samples with carvacrol and the mixture of carvacrol and vitamin E were similar to each other during the entire period of storage.

In contrast to carvacrol, vitamin $\mathrm{E}$ did not prove to have significant antimicrobial effects in vitro. Nevertheless, available evidence suggests that supplementation with vitamin $\mathrm{E}$ enhances the immune response and is associated with increased resistance to several pathogens (Pierpaoli et al., 2010).

\section{Conclusions}

Based on the presented results, we can conclude that carvacrol gave excellent results in suppressing the development of microorganisms, while it showed less effect as an antioxidant in the specific case of the produced co-extrudate. Vitamin E, on the other hand, showed excellent antioxidant activity, but had no significant effect on the growth and development of microorganisms. These two substances did not show any synergistic oxidative effect. Which of the two tested preparations should be used to prolong and improve the storage stability of feed depends on its oxidative and microbial status at the beginning of storage. Vitamin E could be recommended for prolongation of oxidative stability of linseed-sunflower meal co-extrudate, exclusively without addition of carvacrol. If there is a need for a substance with an antimicrobial effect in addition to vitamin E, preliminary tests are neccessary in order to avoid pro-oxidative or inhibitory effects.

\section{Acknowledgements}

The experimental work presented in this paper is a part of the Integrated and Interdisciplinary Research Project funded by the Serbian Ministry of Education, Science and Technological Development, Project No. III 46012.

\section{References}

Burt S., 2004. Essential oils: their antibacterial properties and potential applications in foods - a review. Int. J. Food Microbiol. 94, 223-253

Chen Z.-Y., Ratnayake W.M.N., Cunnane S.C., 1994. Oxidative stability of flaxseed lipids during baking. J. Amer. Oil Chem. Soc. $71,629-632$

Chessari C.J., Sellahewa J.N., 2001. Effective process control. In: R. Guy (Editor). Extrusion Cooking: Technologies and Applications. Woodhead Publishing Limited. Abington, Cambridge (UK), pp. 83-108

Csengeri I., 1996. Dietary effects on fatty acid metabolism of common carp. Arch. Tierernähr. 49, 73-92

Czauderna M., Kowalczyk J., Marounek M., 2011. The simple and sensitive measurement of malondialdehyde in selected specimens of biological origin and some feed by reversed phase high performance liquid chromatography. J. Chromatogr. B, 879, 2251-2258

Dierick N.A., Decuypere J.A., 2002. Endogenous lipolysis in feedstuffs and compound feeds for pigs: effects of storage time and conditions and lipase and/or emulsifier addition. Anim. Feed Sci. Tech. 102, 53-70

Dimić E., Turkulov J., 2000. Quality Control in Technology of Edible Oils (in Serbian). Faculty of Technology. Novi Sad (Serbia), pp. 102

Esterbauer H., Schaur R.J., Zollner H., 1991. Chemistry and biochemistry of 4-hydroxynonenal, malonaldehyde and related aldehydes. Free Radical Biol. Med. 11, 81-128

Firestone D. (Editor), 1989. Official Methods and Recommended Practices of the American Oil Chemists' Society. $4^{\text {th }}$ Edition. American Oil Chemists' Society. Champaign, Ca 5a-40

Gopalakrishnan N., Cherian G., Sim J.S., 1996. Chemical changes in the lipids of canola and flax seeds during storage. Fett-Lipid 98, 168-171

Gordon M.H., 1990. The mechanism of antioxidant action in vitro. In: B.J.V. Hudson (Editor). Food Antioxidants. Elsevier Science Publishers Ltd. (the Netherlands), pp. 1-18

Halliwell B., Gutteridge J.M.C. (Editors), 2007. Free Radicals in Biology and Medicine. Oxford University Press. New York (USA), pp. 888

Hammer K.A., Carson C.F., Riley T.V., 1999. Antimicrobial activity of essential oils and other plant extracts. J. Appl. Microbiol. 86, 985-990 
Hettiarachchy N.S., Barr J., 1991. Effect of additives on the shelf-life stability of lipids in ground flax. In: Program and Exhibit Directory. $52^{\text {nd }}$ Annual Meeting of the Institute of Food Technologists. Chicago (USA), pp. 54-71

Htoo J.K., Meng X., Patience J.F., Dugan M.E., Zijlstra R.T., 2008. Effects of coextrusion of flaxseed and field pea on the digestibility of energy, ether extract, fatty acids, protein, and amino acids in grower-finisher pigs. J. Anim. Sci. 86, 2942-2951

ISO, 2003a. Microbiology of food and animal feeding stuffs - Horizontal method for the enumeration of microorganisms - Colonycount technique at 30 degrees Celsius. International Standard ISO 4833:2003. ISO, Geneva (Switzerland)

ISO, 2003b. Microbiology of food and animal feeding stuffs - Horizontal method for the enumeration of coagulase-positive staphylococci (Staphylococcus aureus and other species) - Part 1 : Technique using Baird-Parker agar medium ISO standard 6888-1:1999/A1:2003. ISO, Geneva (Switzerland)

ISO, 2004. ISO Microbiology of food and animal feeding stuffs Horizontal method for the enumeration of Clostridium perfringens - Colony count technique ISO standard 7937. ISO, Geneva (Switzerland)

ISO, 2006. Microbiology of food and animal feeding stuffs - Horizontal method for the detection of Salmonella spp. ISO standard 6579: 2002/AC: 2006. ISO, Geneva (Switzerland)

ISO, 2008. Microbiology of food and animal feeding stuffs - Horizontal method for the enumeration of yeasts and moulds - Part 2: Colony count technique in products with water activity less than or equal to 0.95 ISO standard 21527-2. ISO, Geneva (Switzerland)

Ivanov D.S., Čolović R.R., Lević J.D., Sredanović S.A., 2012. Optimization of supercritical fluid extraction of linseed oil using RSM. Eur. J. Lipid Sci. Technol. 114, 807-815

Juárez M., Dugan M.E.R., Aldai N., Aalhus J.L., Patience J.F., Zijlstra R.T., Beaulieu A.D., 2010. Increasing omega-3 levels through dietary co-extruded flaxseed supplementation negatively affects pork palatability. Food Chem. 126, 1716-1723

Karlović Đ., Andrić N., 1996. Quality control of oil seeds (in Serbian). Faculty of Technology, Novi Sad, National Insitute of Standardization. Beograd (Serbia), pp. 43

Konieczka P., Rozbicka-Wieczorek A.J., Więsyk E., Smulikowska S., Czauderna M., 2014. Improved derivatization of malondialdehyde with 2-thiobarbituric acid for evaluation of oxidative stress in selected tissues of chickens. J. Anim. Feed Sci. 23, 190-197

Kontush A., Finckh B., Karten B., Kohlschutter A., Beisiegel U., 1996. Antioxidant and prooxidant activity of alpha-tocopherol in human plasma and low density lipoprotein. J. Lipid Res. 37, 1436-1448

Laguerre M., Lecomte J., Villeneuve P., 2007. Evaluation of the ability of antioxidants to counteract lipid oxidation: Existing methods, new trends and challenges. Prog. Lipid Res. 46, 244-282

Lević J., Čabarkapa I., Todorović G., Pavkov S., Sredanović S., Coghill-Galonja T., Kostadinović L., 2011. In vitro antibacterial activity of essential oils from plant family Lamiaceae. Romanian Biotech. Lett. 16, 6034-6041
Lević J., Sredanović S., 2012. Sunflower Meal. Institute of Food Technology. Novi Sad (Serbia), pp. 130

Liang C., Schwarzer K., 1998. Comparison of four accelerated stability methods for lard and tallow with and without antioxidants. JAOCS 75, 1441-1443

Malcolmson L.J., Przybylski R., Daun J.K., 2000. Storage stability of flaxseed. JAOCS 77, 235-238

Michotte D., Rogez H., Chirinos R., Mignolet E., Campos D., Larondelle Y., 2011. Linseed oil stabilization with pure natural phenolic compounds. Food Chem. 129, 1228-1231

Mochiuzuki M., Yamazaki S., Kano K., Ikeda T., 2002. Kinetic analysis and mechanistic aspects of autoxidation of catehins. Biochim. Biophys. Acta 1569, 35-44

Nawar W.W., 1998. Biochemical proceses: lipid instability. In: I.A. Taub, R.P. Singh (Editors). Food Storage Stability. CRC Press LLC. Boca Raton, FL (USA), pp. 89-103

O'Connor J., Perry H., Harwood J., 1992. A comparison of lipase activity in various cereal grains. J. Cereal Sci. 16, 153-163

Pierpaoli E., Viola V., Piolli F., Pirrodi M., Galli F., Provinciali M., 2010. Gamma- and delta-tocotrienols exert a more potent anticancer effect than alpha-tocopheryl succinate on breast cancer cell lines irrespective of HER-2/neu expression. Life Sci. 86, $668-675$

Quéguiner C., Dumay E., Cavalier C., Cheftel J.C., 1989. Reduction of Streptococcus thermophilus in a whey protein isolate by low moisture extrusion cooking without loss of functional properties. Int. J. Food Sci. Technol. 24, 601-612

Rahman M.S., Hossain M.A., Ahmed G.M., Uddin M.M., Yeasmin S., 2008. Studies on the effect of antioxidants on the stability of sesame (Sesame indicum linn.) seed oil during storage. Bangladesh J. Sci. Ind. Res. 43, 235-242

Shaidi F., 2002. Extraction and anlysis of lipids. In: C. Akoh, M. Dekker (Editors). Food Lipids - Chemistry, Nutrition and Biotechnology Inc. New York - Basel, pp. 126-149

SRPS ISO 3960:2011 - Animal and vegetable fats and oils - Determination of peroxide value. Official gazette of Republic of Serbia

StatSoft, Inc., 2011. STATISTICA (data analysis software system). Version 10. www.statsoft.com

Thacker P.A., Racz V.J., Soita H.W., 2004. Performance and carcass characteristics of growing-finishing pigs fed barley-based diets supplemented with Linpro (extruded whole flaxseed and peas) or soybean meal. Can. J. Anim. Sci. 84, 681-688

Ultee A., Bennik M.H., Moezelaar R., 2002. The phenolic hydroxyl group of carvacrol is essential for action against the foodborne pathogen Bacillus cereus. Appl. Environ. Microbiol. 68, 1561-1568

Veldhuizen E.J.A., Tjeerdsma-van Bokhoven J.L.M., Zweijtzer C., Burt S.A., Haagsman H.P., 2006. Structural requirements for the antimicrobial activity of carvacrol. J. Agr. Food Chem. 54, 1874-1879

Zademowski R., Nowak-Polanska H., Rashed A.A., 1999. The influence of heat treatment on the activity of lipo- and hidrophylic components of oat grain. J. Food Process. Preserv. 23, 177-191

Zademowski R., Nowak-Polanska H., Wicklund T., Fomal L., 1997. Changes in oat lipids affected by extrusion. Nahrung 41 , 224-227 